\title{
Reduced Activation Energy of Iron and Copper Ion Doped Mullite which Can Be Used as a Substrate in Electronic Industry
}

\author{
Debasis Roy, Kumaresh Haldar, Biplab Kumar Paul, Alakananda Bhattacharya, Sukhen Das*, \\ Papiya Nandy
}

Physics Department, Jadavpur University, Kolkata, India.

Email: *'sdasphysics@gmail.com

Received June $6^{\text {th }}, 2013$; revised July $10^{\text {th }}, 2013$; accepted July $22^{\text {nd }}, 2013$

Copyright (C) 2013 Debasis Roy et al. This is an open access article distributed under the Creative Commons Attribution License, which permits unrestricted use, distribution, and reproduction in any medium, provided the original work is properly cited.

\begin{abstract}
The crystallized mullite composite has been synthesized via sol-gel technique in the presence of transition metal ions such as iron and copper. The electrical resistivity and activation energy of the composites have been measured and their variation with concentration of the metal ion has been investigated. The resistivity of doped mullite decreases rapidly in the shorter temperature range and sharply in the higher temperature range. The decreasing resistivity is due to the $3 \mathrm{~d}$ orbital electrons and the concentration of metal ions present. X-ray analysis confirms the presence of metal ions in mullite, which entered in the octahedral site. The $\mathrm{Fe}^{2+}$ and $\mathrm{Cu}^{2+}$ ions will substitute $\mathrm{Al}^{3+}$ ion in the octahedral site of mullite structure and most probably will be responsible for reducing the resistivity as well as the activation energy. Transition metal ion doped mullite-based ceramic can be considered as promising material as a substrate in the electronic industry, because of its reasonable atom density, its low activation characteristics, low thermal expansion coefficient and high mechanical strength. The present material we have developed has an activation energy of resistivity/band gap energy, $E g, 1.11 \mathrm{eV}$ at $0.04 \mathrm{M}$ concentration for $\mathrm{Cu}^{2+}$ ion.
\end{abstract}

Keywords: Nanostructures; Sol-Gel Growth; X-Ray Diffraction; Scanning Electron Microscopy (SEM); Electrical Conductivity

\section{Introduction}

Mullite is a material with an important role in the technology of classical and advanced ceramics due to high mechanical strength, low dielectric constant, high creep resistance and low thermal expansion coefficient [1-8]. Mullite based ceramic composites have been continually gaining importance in the insulator and semiconductor industry. Mullite formation starts from $1000^{\circ} \mathrm{C}$ due to solid-state reaction between $\mathrm{Al}_{2} \mathrm{O}_{3}$ and $\mathrm{SiO}_{2}$ particles [9-15].

A wide variety of transition metals enter the mullite structure, Schneider et al. [2-4] has performed a systematic study in order to determine the solubility limit of various transition metal ions, as well as, the location of the corresponding cations in the structure [2-4,7]. The incorporation of transition metal ions strongly depends on their ionic radii and oxidation states, as well as syn-

${ }^{*}$ Corresponding author. thesis procedure. Trivalent cations with ionic radii close to $\mathrm{Al}^{3+}$ can readily be incorporated in mullite structure.

Mullite composites in the presence of various doping agents modifying the mechanical and chemical properties have been reported by many authors. However, literature concerning the activation energy $(E g)$ of metal ions doped mullite composites is relatively few [16-22].

This paper deals with the synthesis of mullite composites doped with varying concentrations of $\mathrm{Fe}^{2+}$ and $\mathrm{Cu}^{2+}$ ions and determines the effect of the same on activation energy of the composites. The divalent cations $(\mathrm{M})$ with larger ionic radii rather react with $\mathrm{Al}_{2} \mathrm{O}_{3}$ forming $\mathrm{MAl}_{2} \mathrm{O}_{4}$ than enter into mullite structure.

The results indicate that the electrical resistivity of the composite varies from order $10^{10} \mathrm{ohm}-\mathrm{cm}$ at $400^{\circ} \mathrm{C}$ to order $10^{5} \mathrm{ohm}-\mathrm{cm}$ at $1300^{\circ} \mathrm{C}$. As the temperature is increasing, the resistivity is decreasing and the activation energy initially decreases up to $0.04 \mathrm{M}$ and then increases [23-25]. 


\section{Experimental}

Mullite precursor gels are prepared from aluminium nitrate nonahydrate $\left(\mathrm{Al}\left(\mathrm{NO}_{3}\right)_{3} \cdot 9 \mathrm{H}_{2} \mathrm{O}\right)$ extra pure (Merck, India), aluminium isopropoxide $\left(\mathrm{Al}(-\mathrm{O}-\mathrm{i}-\mathrm{Pr})_{3}\right)$ puriss (Spectrochem Pvt. Ltd., India.), tetra ethyl orthosilicate $\left(\mathrm{Si}\left(\mathrm{OC}_{2} \mathrm{H}_{5}\right)_{4}\right)$, (Merck, Germany), Iron Nitrate

$\left(\mathrm{Fe}\left(\mathrm{NO}_{3}\right)_{3} \cdot 9 \mathrm{H}_{2} \mathrm{O}\right)(\mathrm{MERCK}$ Specialities Pvt. Ltd., India) and Copper sulphate pentahydrate $\left(\mathrm{CuSO}_{4} \cdot 5 \mathrm{H}_{2} \mathrm{O}\right)$ (MERCK Specialities Pvt. Ltd., India).

For the preparation of precursor gels for mullite synthesis, $\mathrm{Al}(-\mathrm{O}-\mathrm{i}-\mathrm{Pr})_{3}$ and $\mathrm{Si}\left(\mathrm{OC}_{2} \mathrm{H}_{5}\right)_{4}$ were added simultaneously to $0.5 \mathrm{M}$ solution of $\mathrm{Al}\left(\mathrm{NO}_{3}\right)_{3} \cdot 9 \mathrm{H}_{2} \mathrm{O}$ dissolved in $20 \mathrm{ml}$ of distilled water. The molar ratio of $\mathrm{Al}(-\mathrm{O}-$ i- $\mathrm{Pr})_{3} / \mathrm{Al}\left(\mathrm{NO}_{3}\right)_{3} \cdot 9 \mathrm{H}_{2} \mathrm{O}$ was $7: 2$ and mole ratio of $\mathrm{Al} / \mathrm{Si}$ was 3:1 [14].

Doped gels were prepared by adding corresponding metal salt to the original solution in the ratio Al:Si:M, where $\mathrm{M}$ is the concentration of the cobalt salt in molarity. In the final solution, $M$ was varied as $M=0.002\left(G_{1}\right)$, $0.02\left(\mathrm{G}_{2}\right), 0.10\left(\mathrm{G}_{3}\right), 0.15\left(\mathrm{G}_{4}\right)$ and $0.2 \mathrm{M}\left(\mathrm{G}_{5}\right)[12,13]$.

Gel formation was completed after stirring the solution for 3 hours and ageing the sol overnight at $60^{\circ} \mathrm{C}$. The gel was then dried at $110^{\circ} \mathrm{C}$ and after grinding, it takes the form of freely flowing powder. The samples were then pelletized in disc form of $30 \mathrm{~mm}$ diameter and $3 \mathrm{~mm}$ thickness and sintered at $400^{\circ} \mathrm{C}, 800^{\circ} \mathrm{C}, 1000^{\circ} \mathrm{C}$ and $1300^{\circ} \mathrm{C}$ for $3 \mathrm{hr}$ in a muffle furnace under air atmosphere at the heating rate of $10^{\circ} \mathrm{C} /$ minute $[15,18,24,25]$.

The fired pellets were then coated by silver paste on both sides for electrical measurements.

The silver-coated discs were placed in a press-contact type Teflon holder to minimize leakage resistance from the holder. The chamber was made vacuum-tight and properly shielded [23-25].

\section{Instrumentation}

X-ray Powder Diffractometer of D8, Bruker AXS, Wisconsin, USA, using $\mathrm{Cu} \mathrm{K} \alpha$ radiation $(1.5418 \AA$ ) and operating at $40 \mathrm{KV}$ with a scan speed of $1 \mathrm{~s} / \mathrm{step}$, analyzed phase identification of the samples sintered at $1000^{\circ} \mathrm{C}$ and $1300^{\circ} \mathrm{C}$.

The characteristic stretching and bending modes of vibration of chemical bonds of a sample can be effectively evaluated by spectroscopic methods. $1 \%$ of the sample was mixed with spectroscopy grade $\mathrm{KBr}$, pelletized and analyzed by FTIR spectroscopy (FTIR-8400S, Shimadzu).

Electrical resistivity measurements of the sintered gels were carried out by electrometer. A constant DC voltage (V) of about $1.5 \mathrm{~V}$ was applied from a battery across the sample. The voltage (V) across the input resistance was measured by the electrometer.

Morphology of the sintered gels were observed by Field Emission Scanning Electron Microscope (FESEM, model JSM 6700F, JEOL Ltd. Tokyo, Japan).

\section{Results and Discussion}

In the X-ray diffractograms, doped sintered gels shows considerable enhancement in mullite phase at $1000^{\circ} \mathrm{C}$ and $1300^{\circ} \mathrm{C}$ respectively. The sample $\mathrm{G}_{0}$ represents undoped mullite and considerable growth of mullite has been observed at $1000^{\circ} \mathrm{C}$ and $1300^{\circ} \mathrm{C}$ respectively from the diffractograms (Figures 1(a) and (b)). The metal

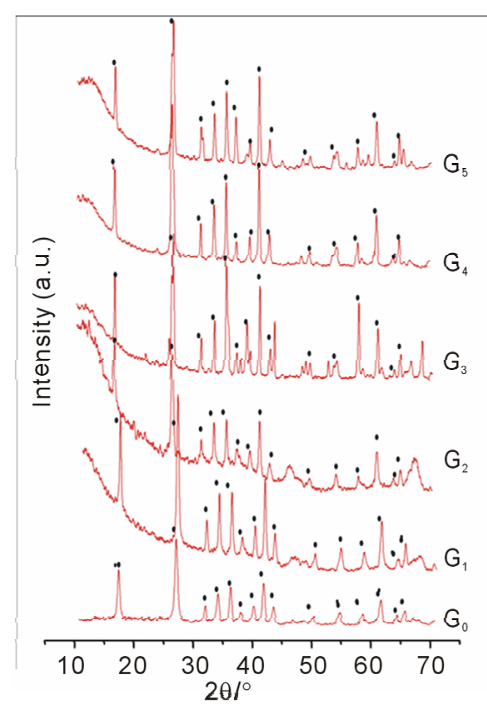

(a)



(b)

Figure 1. $\mathrm{X}$-ray diffraction pattern of mullite precursor gels sintered at $1000^{\circ} \mathrm{C}$ and $1300^{\circ} \mathrm{C}$ containing increasing concentration of iron and copper ion. 
cations have positive effect on the growth of mullite (JCPDS\#15-776) [26] and increases with the increase of concentration of the metal ion at $1000^{\circ} \mathrm{C}$ and $1300^{\circ} \mathrm{C}$ upto $\mathrm{G}_{3}$ (Figures 1(a) and (b)). The "mineralizing" effect of transition metals on phase transformation of mullite is well documented by other authors [16-18]. Interaction of the metal ion with the alumina and silica component of the gel is implicated in accelerated transformation to mullite phase $[16,21,24,25,27]$. The mineralizing effect still continues for the samples $G_{4}$ and $G_{5}$ with respect to $G_{0}$.

From the diffractograms, it was found that with the increase of metal concentration of doped metal, phase transformation in the composite increases. In the diffractograms of $\mathrm{G}_{3}, \mathrm{G}_{4}$ and $\mathrm{G}_{5}$ samples, apart from mullite, $\alpha-\mathrm{Al}_{2} \mathrm{O}_{3}$ (JCPDS\#46-1212) [28] reflections were observed and in $\mathrm{G}_{5}$ other metal phases are observed (Figure 1). In the higher doping concentration mullite formation slightly decreases due to the formation of aluminium oxide and metal oxides [16].

Characteristic bands at wave numbers are observed around 560, 730, 840, 1060 and $1130 \mathrm{~cm}^{-1}$ (Figures 2(a) and (b)) [16]. All the characteristic bands of mullite-561 $\left(\mathrm{AlO}_{6}\right), 741\left(\mathrm{AlO}_{4}\right), 837\left(\mathrm{AlO}_{4}\right), 900\left(\mathrm{AlO}_{4}\right.$-stretching mode) and $1130 \mathrm{~cm}^{-1}$ (Si-O stretching mode) appear in samples $\mathrm{G}_{1}, \mathrm{G}_{2}, \mathrm{G}_{3}, \mathrm{G}_{4}$ and $\mathrm{G}_{5}$. Vibration modes corresponding to doped metal oxide bonds were observed in the FTIR spectra. is

According to, Ohm's law the current $(I)$ in the circuit

$$
I=V / R,
$$

where $V$ is voltage, $I$ is current, and $R$ is the resistance of the load, in this case the sample of metal ion doped mullite. Therefore, the resistance $(R)$ of the sample was calculated as

$$
R=V / I,
$$

In the time of measurement of resistance of each sample, the voltage of the battery was checked The $\rho$ resistivity of a material can be calculated using the relationship

$$
\rho=R(A / l),
$$

where $\rho$ is the material bulk resistivity, $l$ is the sample length, and $A$ is the sample's cross-sectional area perpendicular to the current flow.

The electrical conductivity of the samples were described by the Arrhenius equation as follows

$$
\sigma=\alpha e^{E g / k T}
$$

where $\sigma$ is the electrical conductivity given by $\sigma=1 / \rho$, $\alpha$ is a pre-exponential factor, $T$ is the absolute temperature, $k$ is the Boltzmann constant, and $E_{g}$ is the material's activation energy.

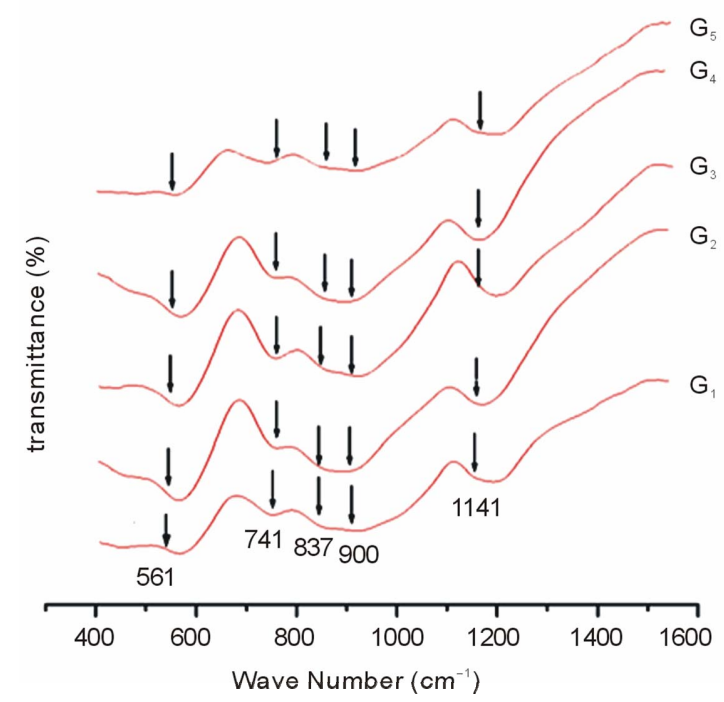

(a)

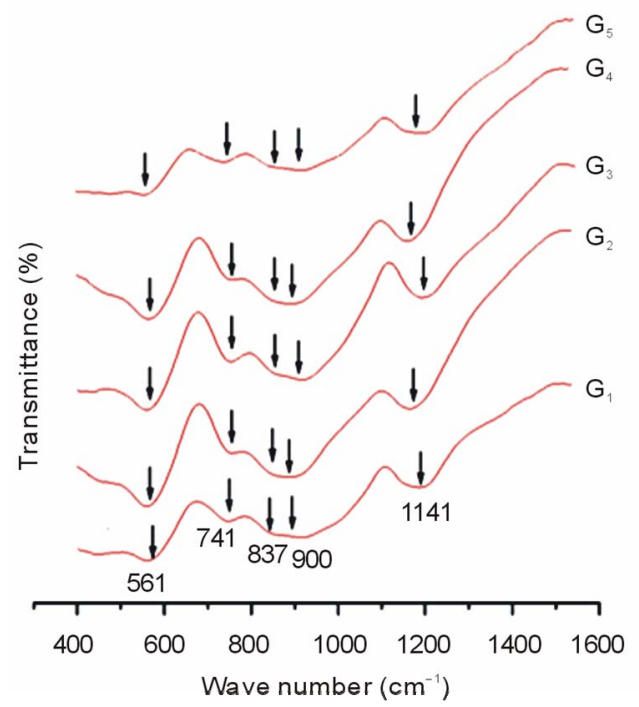

(b)

Figure 2. FTIR bands of mullite precursor gels sintered at $1000^{\circ} \mathrm{C}$ and $1300^{\circ} \mathrm{C}$ containing increasing concentration of iron and copper ion.

The electrical resistivity of the samples were described as

$$
\rho=1 / \sigma
$$

where $\rho$ is the material bulk resistivity and $\sigma$ is the electrical conductivity [23-25].

A plot of $\log _{10} \rho$ versus $1 / T \cdot 10^{4}$ was drawn for each sample at temperatures $400^{\circ} \mathrm{C}, 800^{\circ} \mathrm{C}, 1000^{\circ} \mathrm{C}$ and $1300^{\circ} \mathrm{C}$ (Figures 3(a) and (b)). The plots show a linear increase with the reciprocal temperature.

From the $\log _{10} \rho$ vs sintering temperature $\left({ }^{\circ} \mathrm{C}\right)$ curve (Figures 4(a) and (b)), resistivity decreases with increasing temperature. It has been observed that for con- 




(a)

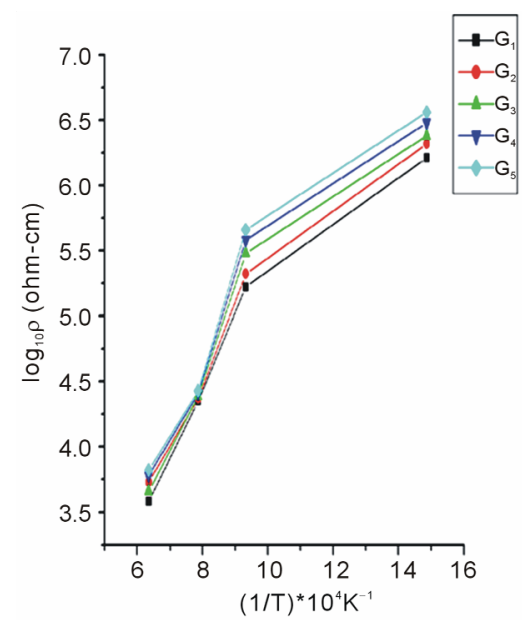

(b)

Figure 3. Resistivity $\left(\log _{10} \rho\right)$ versus $1 / \mathrm{T} * 10^{4}$ graph of mullite precursor gels sintered at $400^{\circ} \mathrm{C}, 800^{\circ} \mathrm{C}, 1000^{\circ} \mathrm{C}$ and $1300^{\circ} \mathrm{C}$ containing increasing concentration of iron and copper ion.

centration $G_{1}$ and $G_{2}$ the resistivity decreases sharply in the higher temperature range, but in the lower temperature range $G_{3}, G_{4}, G_{5}$ decrease rapidly. $G_{1}$ exhibits the lowest resistivity $6.57 \times 10^{5} \Omega \mathrm{cm}$ for $\mathrm{Fe}^{2+}$ and $3.56 \times 10^{5}$ $\Omega \mathrm{cm}$ for $\mathrm{Cu}^{2+}$. The $\mathrm{Fe}^{2+}$ and $\mathrm{Cu}^{2+}$ ions react with $\mathrm{Al}_{2} \mathrm{O}_{3}$ forming metal aluminates and other phases and responseble for decreasing resistivity with sintering temperature.

The activation energy of the samples was calculated in $\mathrm{eV}$ unit from the slope of the plot as follows:

$$
E_{g}=\text { slope } \times 4.606 \times 8.62 \times 10^{-5} \mathrm{eV} \quad[23-25] .
$$

From the $E_{g}$ vs concentration curve, $E_{g}$ decreases with concentration and becomes minimum at $0.04 \mathrm{M}$ for $\mathrm{Cu}^{2+}$ ion concentration (Figure 5).

The substitution of $\mathrm{Al}^{3+}$ ion in the mullite lattice by $\mathrm{Fe}^{2+}$ and $\mathrm{Cu}^{2+}$ ion hampered the electro neutrality of the composite. As a result probably there will be formation



(a)

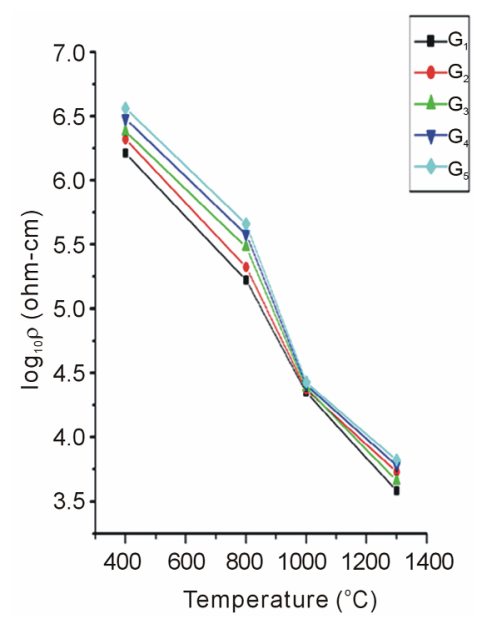

(b)

Figure 4. Resistivity versus Temperature $\left({ }^{\circ} \mathrm{C}\right)$ of mullite precursor gels sintered at $400^{\circ} \mathrm{C}, 800^{\circ} \mathrm{C}, 1000^{\circ} \mathrm{C}$ and $1300^{\circ} \mathrm{C}$ containing increasing concentration of iron and copper ion.

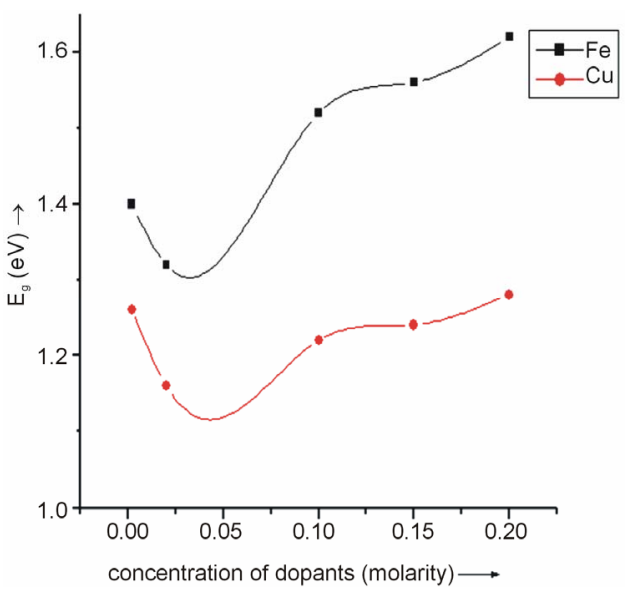

Figure 5. Activation energy $\left(E_{g}\right)$ vs concentration curve of mullite precursor gels sintered at $400^{\circ} \mathrm{C}, 800^{\circ} \mathrm{C}, 1000^{\circ} \mathrm{C}$ and $1300^{\circ} \mathrm{C}$ containing increasing concentration of iron and copper ion. 
of a hole when $\mathrm{Al}^{3+}$ ion is replaced by $\mathrm{Fe}^{2+}$ and $\mathrm{Cu}^{2+}$ ion in the mullite structure [23-25]. It was observed that $\mathrm{Fe}^{2+}$ and $\mathrm{Cu}^{2+}$ ion could not substitute $\mathrm{Al}^{3+}$ ion in mullite but remained there as a cluster. The lowering of resistivity is due to the $3 \mathrm{~d}$ orbital electrons and the concentration of metal ions. The $\mathrm{Fe}^{2+}$ and $\mathrm{Cu}^{2+}$ ion which substituted $\mathrm{Al}^{3+}$ ion in the octahedral site of mullite structure appeared to be efficient in reducing the resistivity [23-25]. There are two possibilities of increase of $E_{g}$ after attaining its minimum value at $0.04 \mathrm{M}$ for $\mathrm{Cu}^{2+}$, either complete incorporation of $\mathrm{Cu}^{2+}$ ion in the mullite structure or dissolution of copper ions in the Si-rich glassy phase. The dissolution of metal ions in the glassy phase should dominate over the incorporation of metal ions into mullite.

Mullite samples, therefore, behave like nonmetallic



(a) electrical conductors, because their conductivity rises faster at lower temperature but slows down at higher temperature.

The morphology of mullite particles with lowest $\left(\mathrm{G}_{1}\right)$ and highest $\left(\mathrm{G}_{5}\right)$ concentrations of $\mathrm{Fe}^{2+}$ and $\mathrm{Cu}^{2+}$ ion sintered at $1000^{\circ} \mathrm{C}$ and $1300^{\circ} \mathrm{C}$ was investigated by FESEM.

The micrograph for $\mathrm{G}_{1}$ shows almost round particles of mullite of an average size of $200 \mathrm{~nm}$. Numerous smaller particles can also be seen along with amorphous aggregates (Figures 6(a) and (b)) [12,29-31].

$\mathrm{G}_{5}$ samples shows distinct acicular morphology of mullite crystals of size $600 \mathrm{~nm}$ embedded in the matrix (Figures 7(a) and (b)). The mullite content and crystallization in all the $G_{5}$ samples were greater than in $G_{1}$ composites, indicating the catalytic effect of the $\mathrm{Fe}^{2+}$ and $\mathrm{Cu}^{2+}$ ions $[16,24,25]$.

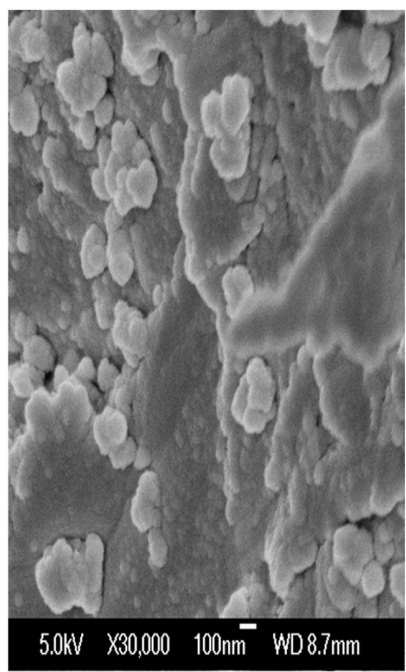

(b)

Figure 6. FESEM of mullite precursor gels doped with iron and copper ion sample $\mathrm{G}_{1}$ sintered at $1000^{\circ} \mathrm{C}$ and $1300^{\circ} \mathrm{C}$.

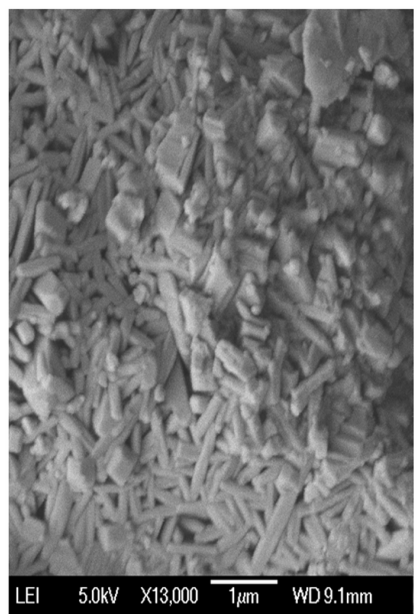

(a)

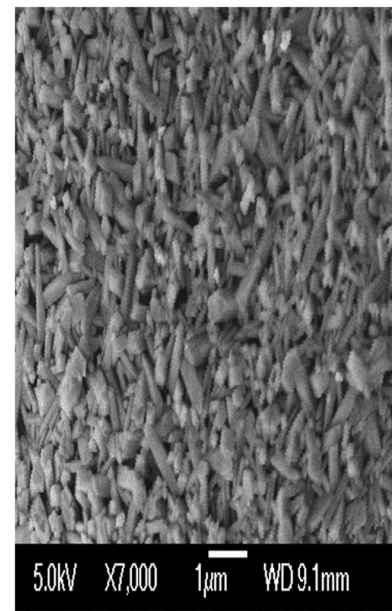

(b)

Figure 7. FESEM of mullite precursor gels doped with iron and copper ion sample $\mathrm{G}_{5}$ sintered at $1000^{\circ} \mathrm{C}$ and $1300^{\circ} \mathrm{C}$. 


\section{Conclusion}

$\mathrm{Fe}^{2+}$ and $\mathrm{Cu}^{2+}$ doped mullite composites have been synthesized by the sol-gel technique, their phase evolution; band gap activation energy has been investigated. The results showed that with increase in $\mathrm{Fe}^{2+}$ and $\mathrm{Cu}^{2+}$ ion concentration the crystallization of mullite was enhanced, which is evident from X-ray diffraction and FESEM of the composites. The activation energy of resistivity/band gap energy, $E g$, attains a minimum value $1.11 \mathrm{eV}$ at 0.04 $\mathrm{M}$ concentration for $\mathrm{Cu}^{2+}$ ion. It has been observed that the resistivity as well as the band gap energy corresponds to semiconductors and due to the low activation energy it can be used as a substrate in the electronic industry.

\section{Acknowledgements}

We are grateful to the members of the, Department of Science and Technology and University Grant Commission (PURSE program), Government of India, for their assistance.

\section{REFERENCES}

[1] I. A. Aksay, D. M. Dabbs and M. Sarikaya, "Mullite for Structural, Electronic, and Optical Applications," Journal of the American Ceramic Society, Vol. 74, No. 10, 1991, pp. 2343-2358. doi:10.1111/j.1151-2916.1991.tb06768.x

[2] H. Schneider, "Kinetics of Crack Tip Blunting of Glasses," Journal of the American Ceramic Society, Vol. 70, No. 1, 1987, pp. 43-48. doi:10.1111/j.1151-2916.1987.tb04851.x

[3] J. Schreuer, B. Hildmann and H. Schneider, "Elastic Properties of Mullite Single Crystals up to $1400^{\circ} \mathrm{C}$," Journal of the American Ceramic Society, Vol. 89, No. 5, 2006, pp. 1624-1631. doi:10.1111/j.1551-2916.2006.00921.x

[4] H. Schneider, J. Schreuer and B. Hildmann, "Structure and Properties of Mullite-A Review," Journal of the European Ceramic Society, Vol. 28, No. 2, 2008, pp. 329-344. doi:10.1016/j.jeurceramsoc.2007.03.017

[5] D. S. Perera and G. Allott, "Mullite Morphology in Fired Kaolinite/Halloysite Clays," Journal of Materials Science Letters, Vol. 4, No. 10, 1985, pp. 1270-1372. doi:10.1007/BF00723478

[6] S. Rahman and S. Freimann, "The Real Structure of Mullite," In: H. Schneider and S. Komarneni, Eds., Mullite, Wiley-VCH, Weinheim, 2005.

[7] M. Schmucker and H. Schneider, "Mullite-Type Gels and Glasses," In: Schneider and S. Komarneni, Eds., Mullite, Wiley-VCH, Weinheim, 2005.

[8] V. V. Vol'khin, I. L. Kazakova, P. Pongratz and E. Halwax, "Mullite Formation from Highly Homogeneous Mixtures of $\mathrm{Al}_{2} \mathrm{O}_{3}$ and $\mathrm{SiO}_{2}$," Inorganic Materials, Vol. 36, No. 4, 2000, pp. 375-379. doi:10.1007/BF02758084

[9] Y. F. Chen, M. C. Wang and M. H. Hon, "Phase Trans- formation and Growth of Mullite in Kaolin Ceramics," Journal of the European Ceramic Society, Vol. 24, No. 8, 2004, pp. 2389-2397. doi:10.1016/S0955-2219(03)00631-9

[10] F. Sahnoune, M. Chegaar, N. Saheb, P. Goeuriot and F. Valdivieso, "Algerian Kaolinite Used for Mullite Formation," Applied Clay Science, Vol. 38, No. 3-4, 2008, pp. 304-310. doi:10.1016/j.clay.2007.04.013

[11] J. Pascual and J. Zapatero, "Preparation of Mullite Ceramics from Coprecipitated Aluminum Hydroxide and Kaolinite Using Hexamethylenediamine," Journal of the American Ceramic Society, Vol. 83, No. 11, 2000, pp. 2677-2680. doi:10.1111/j.1151-2916.2000.tb01614.x

[12] Y. F. Tang ,Z. D. Ling, Y. N. Lu,A. D. Li, H. Q. Ling, Y. J. Wang and Y. Shao, "Study on the Densification of Composite Coating Particles of $\alpha-\mathrm{Al}_{2} \mathrm{O}_{3}-\mathrm{SiO}_{2}$," Materials Chemistry and Physics, Vol. 75, No. 1-3, 2002, pp. 265269. doi:10.1016/S0254-0584(02)00074-3

[13] V. Viswabaskaran, F. D. Gnanama and M. Balasubramanian, "Mullitisation Behaviour of South Indian Clays," Ceramics International, Vol. 28, No. 5, 2002, pp. 557564. doi:10.1016/S0272-8842(02)00010-X

[14] V. Viswabaskaran, F. D. Gnanama and M. Balasubramanian, "Mullitisation Behaviour of Calcined Clay-Alumina Mixtures," Ceramics International, Vol. 29, No. 5, 2003, pp. 561-571. doi:10.1016/S0272-8842(02)00203-1

[15] V. Viswabaskaran, F. D. Gnanama and M. Balasubramanian, "Mullite from Clay-Reactive Alumina for Insulating Substrate Application," Applied Clay Science, Vol. 25, No. 1-2, 2004, pp. 29-35. doi:10.1016/j.clay.2003.08.001

[16] D. Roy, B. Bagchi, S. Das and P. Nandy, "Electrical and Dielectric Properties of Sol-Gel Derived Mullite Doped with Transition Metals," Materials Chemistry and Physics, Vol. 138, No. 1, 2013, pp. 375-383. doi:10.1016/j.matchemphys.2012.11.070

[17] T. Martisius and R. Giraitis, "Influence of Copper Oxide on Mullite Formation from Kaolinite," Journal of Materials Chemistry, Vol. 13, No. 1, 2002, pp. 121-124. doi:10.1039/b206711k

[18] R. S. Aza, S. J. Moya, T. Epicier and G. Fantozzi, "Improved High-Temperature Mechanical Properties of Zirconia-Doped Mullite," Journal of Materials Science Letters , Vol. 9, No. 12, 1990, pp. 1400-1402. doi: $10.1007 / \mathrm{BF} 00721596$

[19] R. Torecillas Imose, Y. Takano, M. Yoshinaka and K. O. Hirota Yamaguchi, "Novel Synthesis of Mullite Powder with High Surface Area," Journal of the American Ceramic Society, Vol. 81, No. 6, 1998, pp. 1537-1540. doi:10.1111/j.1151-2916.1998.tb02513.x

[20] B. L. Kong, T. S. Zhang, J. Ma and F. Boey, "Some Main Group Oxides on Mullite Phase Formation and Microstructure Evolution," Journal of Alloys and Compounds, Vol. 359, No. 1-2, 2003, pp. 292-299. doi:10.1016/S0925-8388(03)00193-2

[21] B. Bagchi, S. Das, A. Bhattacharya, R. Basu and P. Nandy, "Nanocrystalline Mullite Synthesis at a Low Temperature: Effect of Copper Ions," Journal of the 
American Ceramic Society, Vol. 92, No. 3, 2009, pp. 748751. doi:10.1111/j.1551-2916.2008.02910.x

[22] A. Esharghawi, C. Penot and F. Nardou, "Contribution to Porous Mullite Synthesis from Clays by Adding Al and Mg Powders," Journal of the European Ceramic Society, Vol. 29, No. 1, 2009, pp. 31-38. doi:10.1016/i.jeurceramsoc.2008.05.036

[23] S. P. Chaudhuri, S. K. Patra and A. K. Chakraborty, "Electrical Resistivity of Transition Metal Ion Doped Mullite," Journal of the European Ceramic Society, Vol. 19, No. 16, 1999, pp. 2941-2950. doi:10.1016/S0955-2219(99)00058-8

[24] D. Roy, B. Bagchi, S. Das and P. Nandy, "Electrical Resistivity and Activation Energy of Cobalt Acetate Tetrahydrate Doped Mullite," Ceramic-Silikaty, Vol. 56, No. 3, 2012, pp. 222-228.

[25] D. Roy, B. Bagchi, S. Das and P. Nandy, "Dielectric and Magnetic Properties of Sol-Gel Derived Mullite-Iron Nanocomposite," Journal of Electroceramics, Vol. 28, No. 4, 2012, pp. 261-267. doi:10.1007/s10832-012-9725-4

[26] B. L. Kong, T. S. Zhang, J. Ma and F. Boey, "Anisotropic Grain Growth of Mullite in High-Energy Ball Milled Powders Doped with Transition Metal Oxides," Journal of the European Ceramic Society, Vol. 23, No. 13, 2003, pp. 2247-2256. doi:10.1016/S0955-2219(03)00048-7

[27] D. Roy, S. Das and P. Nandy, "Possibility of Decreasing the Activation Energy of Resistivity of Mullite by Doping with Nickel Ion," Material Science-Poland, Vol. 30, No. 4, 2012, pp. 406-413. doi:10.2478/s13536-012-0049-5

[28] M. G. Ferreira da Silva "Role of $\mathrm{MnO}$ on the Mullitization Behavior of $\mathrm{Al}_{2} \mathrm{O}_{3}-\mathrm{SiO}_{2}$ Gels," Journal of Sol-Gel Science and Technology, Vol. 13, No. 1-3, 1998, pp. 987990. doi:10.1023/A:1008652129890

[29] E. Tkalcec, J. Kurajica and J. Schmauch, "Crystallization of Amorphous $\mathrm{Al}_{2} \mathrm{O}_{3}-\mathrm{SiO}_{2}$ Precursors Doped with Nickel," Journal of Non-Crystalline Solids, Vol. 353, No. 30-31, 2007, pp. 2837-2844. doi:10.1016/j.jnoncrysol.2007.06.011

[30] W. Z. Lv, Q. Qi, F. Wang, S. H. Wei, B. Liu and Z. K. Luo, "Sonochemical Synthesis of Cobalt Aluminate Nanoparticles under Various Preparation Parameters," Ultrasonics Sonochemistry, Vol. 17, No. 5, 2010, pp. 793-801. doi:10.1016/j.ultsonch.2010.01.018

[31] D. Roy, B. Bagchi, A. Bhattacharya, S. Das and P. Nandy, "The Influence of Cobalt Acetate on Sol-Gel Derived Mullite Densification Behaviour," Journal of Wuhan University of Technology-Mater. Sci. Ed., Vol. 27, No. 5, 2012, pp. 836-840. doi:10.1007/s11595-012-0558-4 